\title{
From Crisis to Creativity: Towards a Psychology of Creating
}

\author{
Brady Wagoner \\ Aalborg University, Denmark \\ E-mail address: wagoner@hum.aau.dk
}

ARTICLE INFO

\section{Keywords:}

Creating

Evaluating

Social process

Article history:

Received 5 November 2014

Received in revised form 19 December 2014

Accepted 20 December 2014

ISSN: 2354-0036

DOI: $10.1515 /$ ctra-2015-0010

\author{
A B STRACT
}

"The history of psychology is actually only a history of crisis" announced Husserl (1970 [1954], p. 203) over fifty years ago. Indeed, almost since the beginning of modern psychology, psychologists have talked about it being in crisis. Many of the 'symptoms' of crisis recently pointed out by Glăveanu (2014) with regard to the psychology of creativity, have been discussed in relation to psychology as a whole - for example, fragmentation and lack of theoretical integration (Vygotsky, 1927), units of analysis that do not capture the whole (Dreisch, 1925), and the lack of meaningfulness of research and pretence of ideological neutrality (Bühler, 1927). Similarly, in social psychology, Sherif (1977) saw a crisis in the tendency of psychologists to make the discipline scientific by imitating the natural sciences, 'the rich relatives,' rather than creating their own theories and methods (see also Kim, 1999).

Valsiner (2012, p. 153) notes that "'Being in crisis' would be a normal state for any enterprise of knowledge construction where the previously created understanding of the phenomena is constantly under challenge by new ideas and evidence". He adds that we need to be careful so as not to get caught up in the rhetoric of crisis and worry too much about 'doing things in the right way' in relation to some position in the field (whether it be behaviourism, cognitivism, the mainstream, etc.), rather than getting on with the do- 
ing itself. Crisis talk occurs not so much from a particular state-of-affairs in relation to research products, but when psychologists have difficulties collaborating among themselves or with other communities (Zittoun, Gillespie \& Cornish, 2010). This is not always lamentable; it may signal differentiation into multiple complimentary approaches, such as neural, psychological and social.

Having pointed out that Glăveanu's (2014) inventory of crisis symptoms has been around psychology for some time and that crisis talk is not always productive, I must say that I appreciate the critique Glăveanu (2014) has provided in the field of creativity research. And I share with him the belief that we should expect more creative research practices from a discipline that takes creativity as its object of investigation! Moreover, I agree with his six general principles for working towards this. In the remaining space of this short commentary I would like to put forward a couple of concrete theoretical and methodological suggestions for making creativity research more creative.

Firstly, let me put my assumptions on the table: I broadly understand creativity as a basic feature of the human condition. It is one of the features that differentiates human beings from other animals. When the human creates, s/he does so with some idea of what $\mathrm{s} /$ he is building, whereas for the bird or the bee, this comes instinctually. In other words, the human being is oriented towards the future in a way that alters his/her present (Vygotsky, 1930). But this broad understanding of creativity makes it a rather ephemeral object; in human affairs it is everywhere and nowhere at the same time. When we look at how the word has been used in popular discourse, it has a rather short history, and an even shorter one in scientific discourse. If there is difficulty defining long standing concepts such as memory (Danziger, 2008; Wagoner, 2012) then the case is even more complicated with creativity.

A solution offered in relation to memory has been to look at the concrete practice of remembering (Bartlett, 1932; Harré, 2000). Rather than starting with a circumscribed mental entity - the memory - the focus shifts to an observable activity that involves a myriad of different processes. This is not a capacity or skill that can be analysed independently of the context in which it occurs and the material on which it works. Similarly, with regard to creativity, we would need to focus our attention on the concrete practices of creating and of evaluating those creations within a social field. With this focus we sidestep getting caught up in definitions of creativity - problems which Glăveanu (2014) has already highlighted - and jump right into a clearly definable unit of analysis, that is a whole person or persons creating something within a context that is both social and material (Tanggaard, 2013) and the struggle to get it recognized there. 
Given this analytic focus it follows that we need to develop methodologies to study creating as an ongoing process in which something qualitatively new can emerge. Standard methods that look for cause or correlational relations between variables are blind to process and therefore will not help us in this. In contrast, psychologists have developed a number of methods aimed at triggering, capturing and analyzing qualitative transformations, such as microgenetic methods (Wagoner, 2009). Rather than looking for the causes of participants' behavior through the manipulation of variables, these methodologies consider the person themselves as an active agent in the situation, an agent who can construct something new and unpredictable to deal with the task demands. Vygotsky's experiment in which children could use picture cards to help them remember lists of words is a good case in point. One child creatively used a picture of a crab on a beach to help remember the word 'theatre' with the phrase 'the crab is looking at the stones on the bottom, it is beautiful, it is a theatre' (Vygotsky, 1987, p. 181). The child was constructing a totally new structure in order to solve the memory task.

Glăveanu himself has developed a number of creative methods for examining the process of creation. For example, he has had Easter egg decorators wear a SubCam (subjective camera) in order to see the craft through their eyes and scrutinize the almost invisible moment-to-moment forms of innovation in the process (see Glăveanu and Lahlou, 2012). In a similar study, he has had a painter do the same, but has interviewed him with video afterwards, to further interrogate the artist's subjective process. Such methods get close to the concrete action of creativity and allow us to follow its course as it is happening. In this, new methods are being invented to best explore the phenomena under investigation. It should also be noted that the researcher is not merely a technician here, but rather his or her subjectivity and insight plays a key role in the research process. The researcher has to use his or her imagination to reconstruct the process being investigated.

On a final note, the process of creation need not be studied from an individual perspective; it can also be explored as part of a wider social process. An early example of such an approach comes from Frederic Bartlett's (1923) study of what he called 'social constructiveness,' the development of new cultural forms through the welding together of many different social influences. He discussed the growth of a new religion within a Native American group through bringing together bits and pieces of other religions with their indigenous beliefs. In this process, he pointed out that the final outcome could not be predicted by any single individual in the group, but rather involved their complex relation through time. Moreover, he said that groups also have an orientation to the fu- 
ture, or what he called their 'prospect,' which shapes their action in the present. A more modern example can be found in Moscovici's (1976) study of how psychoanalysis was systematically transformed as it came into contact with the French public. In both cases, we have an analysis of something qualitatively new emerging through time within a social process. Perhaps we can expect a similar process to occur among creativity researchers in the near future.

\section{REFERENCES}

Bartlett, F.C. (1932). Psychology and Primitive Culture. Cambridge: Cambridge University Press.

Bühler, K. (1927). Die Krise der Psychologie ["The crisis of psychology”]. Jena: Verlag Gustav Fischer.

Danziger, K. (2008). Marking the Mind: The history of memory. Cambridge: Cambridge University Press.

Glăveanu, V. (2014). The psychology of creativity: A critical reading. Creativity 1, 1, 1032; DOI: 10.15290/ctra.2014.01.01.02.

Glăveanu \& Lahlou (2012). 'Through the creator's eyes': Using the subjective camera to study craft creativity. Creativity Research Journal, 24, 152-162.

Harré, R. (2000). Cognitive Science: A Philosophical Introduction. London: Sage.

Husserl, E. (1970[1954]). The Crisis of European Sciences and Transcendental Phenomenology. Evarston, IL: Northwestern University Press.

Kim, U. (1999). After the "Crisis" in Social Psychology: The Development of the Transactional Model of Science. Asian Journal of Social Psychology, 2, 1, 1-19.

Moscovici, S. (2009[1976]). Psychoanalysis: Its image and its public. Cambridge: Polity Press.

Sherif, M. (1977). Crisis in social psychology: Some remarks towards breaking through the crisis. Personality and Social Psychology Bulletin, 3, 368-382.

Tanggaard, L. (2013). The sociomateriality of creativity in everyday life. Culture \& Psychology, 19, 1, 20-32.

Valsiner, J. (2012). A Guided Science: Psychology in the Mirror of its Making. New Brunswik: Transaction Publishers.

Vygotsky, L. S. (1930/2004). Imagination and creativity in childhood. Journal of Russian and East European Psychology, 42, 1, 7-97.

Vygotsky, L. S. (1987[1927]). The Historical Meaning of The Crisis in Psychology: A Methodological Investigation. The Collected Works of Vygotsky. New York: Plenum Press. 
Vygotsky, L. S. (1987). History of development of higher mental functions. The Collected Works of Vygotsky (vol. 4) (pp. 69-235). New York: Plenum.

Wagoner, B. (2009). The Experimental Methodology of Constructive Microgenesis. In J. Valsiner, P. Molenaar, N. Chaudhary and M. Lyra (Eds.). Handbook of Dynamic Process Methodology in the Social and Developmental Sciences (pp. 99-121). New York: Springer.

Wagoner, B. (2012). Culture in Constructive Remembering. In J. Valsiner (Ed.), Oxford Handbook of Culture and Psychology (pp. 1034-1055). Oxford: Oxford University Press.

Zittoun, T., Gillespie, A. \& Cornish, F. (2009). Fragmentation or differentiation: questioning the crisis in psychology. Integrative psychological and behavioral science, 43, 2, 104-115.

Corresponding author at: Brady Wagoner, Department of Communication and Psychology, Aalborg University, Kroghstraede 3, DK-9220 Aalborg, Denmark E-mail: wagoner@hum.aau.dk 